\title{
Rafael Chirbes y Laura Restrepo. Dos posturas ético-estéticas y dos propuestas de justicia y memoria
}

\author{
Janneth Español Casallas \\ Universidad de Granada
}

\begin{abstract}
Resumen:
Interpretamos las poéticas del español Rafael Chirbes y de la colombiana Laura Restrepo como ficciones memorialistas. Cada uno de los autores reinterpreta en la ficción hechos históricos de un pasado violento, a saber: la Guerra Civil y el franquismo (Chirbes), los orígenes del conflicto armado colombiano (Restrepo). Teniendo en cuenta que el concepto de memoria en la contemporaneidad ha girado en torno a la justicia y al derecho enfocándose en la comprensión de crímenes atroces ocurridos en el pasado de una sociedad, este artículo pretende responder a las siguientes preguntas: ¿qué aportan las ficciones En la orilla de Rafael Chirbes y La novia oscura de Laura Restrepo al discurso jurídico-político?; ¿qué aporte introducen esas ficciones al campo de la memoria y la justicia?
\end{abstract}

Palabras clave: memoria, literatura, justicia, violencia, Guerra Civil española, conflicto armado colombiano

\begin{abstract}
:
We interpret the poetics of the Spanish writer Rafael Chirbes and the Colombian writer Laura Restrepo as fictions of historical memory. Both authors turn historical events into fiction, namely: the Civil War and Franco's regime (Chirbes) and the origins of the Colombian armed conflict (Restrepo). Taking into consideration that the concept of memory in the contemporary discourse is related to justice and law and focusing on the understanding of atrocious crimes that occurred in the past of a society, this article aims to answer the following questions: What do the fictions En la orilla by Rafael Chirbes and La novia oscura by Laura Restrepo contribute to the legal-political discourse? What is their contribution to the field of memory and justice?
\end{abstract}

Keywords: memory, literature, justice, violence, Spanish Civil War, Colombian conflict

En las siguientes líneas haremos una lectura de las obras En la orilla (2013) de Rafael Chirbes y La novia oscura (1999) de Laura Restrepo desde un enfoque analítico de los estudios que relacionan derecho y literatura en el ámbito iberoamericano (Botero; Calvo; Roggero). Siguiendo al profesor y jurista colombiano Botero Bernal, poner una obra literaria como objeto de análisis teórico-jurídico significa suponer que la obra literaria refleja una cultura jurídica de interés para el investigador/lector. Esto significa poner en contacto discursos de la disciplina jurídica con el tema también jurídico que distinguimos en la obra literaria (Botero 36-37). Hemos identificado la narrativa de Restrepo y de Chirbes como ficciones memorialistas. Cada uno de los autores 
reinterpreta en la ficción hechos históricos de un pasado violento, a saber: los orígenes del conflicto armado colombiano (Restrepo) y la Guerra Civil y el franquismo (Chirbes). Ahora bien, el concepto de memoria en la contemporaneidad ha girado en torno a la justicia y al derecho enfocándose en la comprensión de crímenes atroces ocurridos en el pasado de una sociedad (Mate; Winter). En efecto, hay una relación esencial entre la memoria y la narración de acontecimientos violentos: la memoria obliga a repensar cómo se construye la historia "es decir, el lugar de la violencia en la política" (Mate 169). Nos ubicamos en el corazón de nuestro tema, abordaremos la violencia, su relación con la justicia y con el derecho. Las novelas En la orilla y La novia oscura refieren una postura ético-estética en lo que respecta a la violencia. Comprender esta postura puede a su vez darnos una clave de su concepción de justicia y de derecho.

Nos adherimos a los estudios críticos de la literatura memorialista que afirman que determinadas formas de ficcionalización operan en función de que el lector revise sus propios patrones de comprensión histórica y que el uso de determinados recursos narrativos empleados en la ficción encauzan una revisión del pasado. Todo lo cual permite que el discurso literario sea considerado como un discurso más en el conglomerado de los discursos sociales (Lauge Hansen). De manera que la narrativa que reinterpreta el pasado no solo dialoga con los discursos sociales que revisan la historia de acontecimientos violentos, sino que puede enriquecer o reconfigurar la memoria cultural que circula en una sociedad. Dicho lo anterior, las preguntas que guían nuestro escrito son: ¿Qué aportan las ficciones En la orilla y La novia oscura al discurso jurídicopolítico?; ¿qué aporte introducen esas ficciones al campo de la memoria y la justicia? Nos disponemos a indagar una cultura jurídica legible en las novelas referidas a partir de comprender la postura ético-estética en la ficcionalización de la violencia (Rancière). ${ }^{1}$ Partimos de la afirmación de que la postura frente a la violencia está relacionada con determinada visión de la justicia y de derecho. Así pues, indagar en la ficción la postura ético-estética respecto de la violencia nos puede informar determinada concepción de justicia de derecho y también de memoria.

\section{Justicia y derecho. Memoria y violencia}

Jacques Derrida en su ensayo traducido al español como Fuerza de ley, el fundamento mistico de la autoridad (1991) aborda las dos temáticas de nuestro interés, la primera, la relación de la justicia con el derecho, la segunda, la relación del derecho con la violencia. En el título de su ensayo Derrida anuncia las aporías y los deslizamientos entre derecho y justicia. Fuerza de ley, en inglés to enforce the law "nos recuerda que si la justicia no es necesariamente el derecho o la ley, aquella no puede convertirse en justicia de derecho o en derecho [...] si no apela a la fuerza" (Derrida 25-26). Esto quiere decir que, aunque la justicia trascienda lo jurídico no hay justicia que se desligue de una

\footnotetext{
${ }^{1}$ Siguiendo a Rancière hay una concurrencia de significados entre arte, ética y política. El arte como lo político "hace ver lo que no tenía razón para ser visto, hace escuchar un discurso allí donde sólo el ruido tenía lugar, hace escuchar como discurso lo que no era escuchado más que como ruido." (Rancière 45) El arte y lo político apuntalan a que determinado objeto o escenario sean susceptibles de ser hendidos o fracturados en su interior. En otras palabras, lo poético-estético como lo ético-político consisten en reconfigurar la mirada, la percepción y la significación sobre un objeto u escenario dado.
} 
historia de la legalidad. Y esta justicia en tanto derecho siempre implica la fuerza, es decir, la coacción:

sucede que el derecho pretende ejercerse en nombre de la justicia y que la justicia exige instalarse en un derecho que exige ser puesto en práctica (constituido y aplicado) por la fuerza (enforced) (Derrida 51).

La justicia (la que no es derecho o ley) es una "aporía”, que al decir del argelino significa lo que está en oposición a una experiencia. Esta (la experiencia) es una travesía, un pasaje hacia un destino al que se transita y que, valga la redundancia, se experimenta. La aporía, al contrario, es aquello que no permite el pasaje: la "(a)poría es un no-camino. La justicia sería, desde este punto de vista, la experiencia de aquello de lo que no se puede tener experiencia" (Derrida 38). De manera que la justicia (que no es derecho o ley) se sitúa ante lo venidero, es una espera o un deseo, una exigencia o una justa apelación, la justicia implica un por-venir.

Quizás es por eso por lo que la justicia, en tanto que no es sólo un concepto jurídico o político, abre al porvenir la transformación, el cambio o la refundación del derecho y de la política. "Quizás", hay que decir siempre quizás para la justicia (Derrida 63-64).

La justicia se abre al porvenir, a la espera de alcanzar el derecho o ley. Y es en este punto que nos trasladamos a la relación entre derecho y violencia. Porque es en los momentos de refundación del derecho cuando sale a la luz la violencia que le es inmanente. Todo momento fundador de poder o de derecho interrumpe y suspende el derecho establecido para fundar otro, se basa en una "instancia de no derecho" y se apoya en la violencia. Dice Derrida:

Hay en primer término la distinción entre dos violencias del derecho, dos violencias en cuanto al derecho: la violencia fundadora, la que instituye y establece el derecho (die rechtsetzende Gewalt), y la violencia conservadora, la que mantiene, confirma, asegura la permanencia y la aplicabilidad del derecho (die rechtserbaltende Gewalt) (Derrida 82).2

Gewalt, que significa la violencia autorizada o la fuerza de ley, es la palabra alemana que Walter Benjamin utiliza en su ensayo Zur Kritike der Gewalt (1921), traducido al español como Para la crítica de la violencia, en el cual argumenta que toda crítica al concepto de violencia revisa el campo del derecho. Es Benjamin el que distingue entre las dos violencias que son inherentes al derecho y las cuales señala también Derrida en la cita. ${ }^{3}$ Esto es: la violencia fundadora de derecho y la violencia que se ejerce una vez que este derecho se ha establecido y se debe mantener, que es la violencia conservadora. Dice Benjamin:

La función de la violencia en el proceso de fundación de derecho es doble. Por una parte, la fundación de derecho tiene como fin ese derecho que, con la violencia como medio, aspira a implantar. No obstante, el derecho, una vez establecido, no renuncia a la violencia.

\footnotetext{
${ }^{2}$ Derrida conserva la traducción Gewalt en lugar de violencia ya que Gewalt además de violencia significa también violencia autorizada, soberanía del poder legal o fuerza de ley.

${ }^{3}$ La segunda parte del ensayo publicado en español como Fuerza de ley: El "fundamento místico de la autoridad" que venimos abordando, dialoga con el texto de Walter Benjamin Zur Kritik der Gewalt.
} 
Lejos de ello, solo entonces se convierte verdaderamente en fundadora de derecho en el sentido más estricto y directo, porque este derecho no será independiente y libre de toda violencia, sino que será, en nombre del poder, un fían íntima y necesariamente ligado a ella (Benjamin, Violencia 40).

En síntesis, la violencia no es exterior al orden del derecho. La violencia fundadora de poder o de derecho no puede justificarse mediante ninguna ley pre-existente, es aquí donde se pone al desnudo la violencia del orden jurídico. La fundación de todos los Estados acaece en una situación que inaugura un nuevo derecho y lo hace siempre desde la violencia y fuera de la ley, el momento fundador del derecho es así una instancia de "no-derecho". Derrida dirá: "Ese momento tiene siempre lugar y no tiene jamás lugar en una presencia [...] un acto realizativo puro que no tendría que dar cuenta a nadie ni ante nadie" (93). Esta misteriosa frase se traduce en el hecho de que cada vez que la ley se aplica está a su vez re-fundándose. Es decir, no hay una oposición entre una violencia que funda derecho y la que lo conserva, sin embargo, esta violencia conservadora aparece como invisible. Tal vez esto explique la dificultad y la polémica que produce señalar la violencia en directa relación con el derecho y la persistencia en relacionar más bien el binomio, derecho y paz.

Lo que devela Derrida del también enigmático texto de Benjamin es que el individuo está siempre en la posición del campesino del cual habla Kafka en su leyenda Ante la ley (1915). ${ }^{4}$ Una ley todavía por venir, situación ordinaria y terrible del hombre que no llega a ver ni a alcanzar la ley: "puesto que esta es trascendente en la medida misma en que es él quien debe fundarla como todavía por venir, en la violencia." (Derrida 93) $\mathrm{Y}$ aquí el temor que el Estado tiene de otra "violencia fundadora" esto es, capaz de transformar las relaciones de derecho y de presentarse como "teniendo derecho al derecho" (90).

Ahora bien, tras la violencia fundadora, por lo general terrorífica, acompañada de genocidios, torturas, deportaciones, le sigue una suerte de auto-legitimación de un Estado de derecho precario. Y aquí una aporía, porque ningún poder fundante está autorizado por una legitimidad anterior. Así que la violencia fundante no es, en principio, ni legal, ni ilegal (Derrida 18). Tras estos acontecimientos fundacionales de poder y de derecho viene la memoria a desempeñar su función. Así lo expresa Ricœur:

Lo que debe evocarse aquí es la relación fundamental de la historia con la violencia. No se equivocaba Hobbes al afirmar que la filosofía política tiene su origen en una situación originaria en la que el temor a la muerte violenta empuja al hombre del «estado de naturaleza» a los vínculos de un pacto contractual que le garantizará, ante todo, la seguridad; por otra parte, no existe comunidad histórica que no haya nacido de una relación que se puede asimilar sin ninguna duda a la guerra. Lo que celebramos con el nombre de acontecimientos fundadores son esencialmente actos violentos legitimados después por un estado de derecho precario. Lo que fue gloria para unos fue humillación para los demás. A

\footnotetext{
${ }^{4}$ Walter Benjamin ha estado fuertemente influenciado por los escritos de Kafka. Mantuvo una correspondencia con Adorno, Sholem y Werner Kraft acerca de la narrativa del autor de Praga, la cual, solo hasta hace pocos años ha sido traducida al español en el interesante libro titulado: Sobre Kafka, Textos, discusiones y apuntes (2014). Llama la atención que Benjamin en su intercambio con Sholem había redactado unas "Tesis sobre el concepto de justicia" en 1916, que según afirmaba, estaban en relación directa con la narrativa sobre Kafka (véase Benjamin, Kafka).
} 
la celebración de un lado, corresponde del otro la execración. Así se almacenaron en los archivos de la memoria colectiva heridas simbólicas que exigen curación (Ricœur 109).

La primera parte de la cita de Ricœur refiere a Thomas Hobbes que en su teoría clásica de la formación del Estado plantea el presupuesto teórico de un estado de naturaleza de los hombres en el que reina el conflicto permanente, bellum omnium contra omnes o la guerra de todos contra todos. Así, en ese estado de naturaleza pervive una "violencia natural" que se interrumpe con el "pacto social" o acuerdo en el que los hombres deciden crear un "animal artificial" que es el Leviatan, un gran monstruo que administrará la ley y la violencia, y que no es otra cosa que el Estado (Hobbes). La teoría de Hobbes es actual ya que nos remite a los presupuestos básicos del Estado y particularmente, al hecho de que la violencia se remite al derecho y al Estado que la monopoliza. En oposición a este relato que vincula el derecho y violencia, lo que refiere la crítica de Benjamin es que esta ligazón de la violencia con el orden jurídico remite a una justicia que, digámoslo así, no es una justicia pura sino una justicia ligada al derecho, Benjamin la llama justicia mítica. En su crítica a esta justicia vinculada al derecho y a la violencia, se encamina a defender una "violencia pura", que está relacionada directamente con su concepción de justicia. Se trata de una violencia que no busca su legitimidad en el derecho, sino que se aparta de él, incluso, apunta a que sea "capaz de paralizar a la violencia" autorizada por el derecho y el Estado (Benjamin, Violencia 41). En síntesis, la justicia a la que apela el crítico enterrado en el Cementerio de Portbou es a una justicia ligada a la "violencia revolucionaria":

Pero si la violencia llega a tener, más allá del derecho, un lugar asegurado como forma limpia e inmediata, se deduce, independientemente de la forma y posibilidad la violencia revolucionaria, a qué nombre debe atribuirse la más elevada manifestación de la violencia a cargo del hombre (Benjamin, Violencia 44)

Expuesto lo anterior, presentamos una lectura de las novelas En la orilla y La novia oscura aludiendo a los acontecimientos fundacionales presentes en estas ficciones, así como a la violencia conservadora que los preserva en el tiempo. Afirmamos que la poética En la orilla articula un concepto de justicia benjaminiano. Es legible en esta ficción la "violencia pura", es decir, fuera del derecho. Lo cual a su vez quiere decir que la concepción de memoria en esta ficción, si bien apela a la justicia la desliga de la ley y del derecho. En cuanto a la ficción de La novia oscura, distinguimos que no hay un único y definitivo acontecimiento fundador de derecho, lo que es legible son ordenes sociales que pretenden ser fundantes sin lograrlo del todo. En esta ficción hay una concepción moralizante de la violencia que encamina una propuesta de justicia, no necesariamente dentro de la ley, pero sí dentro de un mito fundador válido que la organice.

\section{En la orilla. Una propuesta benjaminiana de justicia y memoria}

En la orilla (2013) está dividida en tres partes que se titulan: "1. El hallazgo", "2. Localización de exteriores" y "3. Éxodo". Las dos primeras partes están fechadas 
respectivamente así: "26 de diciembre de 2010" y "14 de diciembre de 2010" y la última parte no tiene fecha, aunque se entiende que ocurre o bien un día antes al 14 de diciembre de 2010 o ese mismo día. La segunda parte es la que abarca con predominio la extensión de esta novela de más de cuatrocientas páginas cuya prosa se eleva a fuerza simbólica de lo que cuenta: un presente de devastación, crisis y dispersión. Un mundo que demanda un nuevo lenguaje con la capacidad de capturar la elocuencia del estado de cosas que consiste en un presente pos-apocalíptico cargado de las contradicciones del pasado de la Guerra Civil, del franquismo y del posfranquismo. Esto explica porqué, pese a que estamos ante una novela sin argumento o trama, sí hay una tensión y significación de lo representado, que se logra gracias a un lenguaje despiadado, tenso, movedizo que se dispersa todo el tiempo como si no llegara a fijar una sola y única verdad (Eusebio; Carcelén et al. 12-13). Los acontecimientos políticos referentes a la historia de España se aúnan con el presente de devastación y crisis ocurrido tras el conocido "pelotazo" o boom inmobiliario de principios de siglo XXI. De manera que la novela abarca diversos tiempos, el tiempo narrativo de los dos días del año $2010 \mathrm{y}$ el tiempo de la memoria que nos traslada, literalmente, a "saltos", a los tiempos de la Guerra Civil, el franquismo y el posfranquismo. Para esto la ficción nos ubica entre tres lugares: Misent, pueblo hiper-construido en función de veraneantes y especuladores inmobiliarios del que ya solo quedan grúas, construcciones paralizadas y el ajetreo de la prostitución; Olba, pueblo más bien modesto donde residen las familias oriundas de la zona y trabajadores emigrantes que en un tiempo se beneficiaron de la economía Misent; y el marjal de Olba, una ciénaga que conserva su naturalidad y que pese a su terreno pantanoso ha sido beneficioso para los solitarios que saben pescar y cazar. De manera que Misent es el prototipo de cualquier pueblo o ciudad de veraneantes de la costa mediterránea española, así como de cualquier otro lugar donde el negocio inmobiliario y la economía de servicios han transformado el paisaje natural y social. Nos ubicamos ante una narrativa radicalmente realista interesada en capturar el paisaje político, social y sentimental de la España del siglo XXI en conexión con el tiempo histórico del siglo XX de este país (Valls; Basanta).

La crítica literaria distingue en la obra narrativa de Chirbes una recurrencia a figuras metafóricas animalescas y descarnadas muchas veces inspiradas, entre otros, en la pictórica de Francis Bacon, de Lucien Freud o de Francisco Goya (Labrador; López et al.; López M.). Fernando Valls, por ejemplo, en sus comentarios sobre la novela de La Larga Marcha, dice que la metáfora y la simbología del perro refiere una postura narrativa que rompe los esquemas maniqueos del mito de las dos Españas (Valls 136). ${ }^{5}$ Desde nuestro punto de vista, ésta simbología animal, que llamamos estética de la animalidad, está en conexión con una postura ético-política legible en todos los textos del ciclo chirbesiano, ${ }^{6}$ que apunta a cuestionar la legitimidad de los mitos fundacionales: la Guerra Civil y la Transición.

${ }^{5}$ Valls señala que esta simbología no alude solamente a tal o cual personaje por su condición social o ideológica. Por el contrario, como dice, rompe esquemas maniqueos: "desde el momento en que vencedores y vencidos, trabajadores y burgueses, sufren todos las consecuencias de la guerra. Todo ello se presenta a través de una narración realista, aunque se valga de símbolos como el pantano, las manos, los perros" (Valls 136).

${ }^{6}$ Llamamos chirbesiano al ciclo narrativo del autor que está en medio de su primera y última ficción. Esto es, toda su novelística excepto Mimoun y Paris-Austerlit: 
Particularmente, en En la orilla la estética de la animalidad robustece la ficción de la violencia aludiendo a la antropofagia y a la cadena trófica que caracteriza la historia de vida de todos los personajes. Desde el punto de vista de Esteban, voz principal de esta novela, sabemos de la historia de los otros personajes, también es él quien marca los tiempos del relato el cual, como hemos dicho, parte desde el vértigo de un presente de crisis y se aúna con el tiempo del pasado de la Guerra Civil, franquismo, posfranquismo, zigzagueando constantemente con el devenir. En todos los tiempos se distingue lo mismo: la cadena trófica humana en la que eres el plato comido o el que se lo come o como sugiere la voz de Esteban: "Hay lo que hay. No aparece el reino moral por ninguna parte. Estás abajo porque no te has desanimalizado lo suficiente" (82). Sigamos la voz de Esteban aludiendo a esa cadena trófica que lo rodea, refiriéndose a su línea paterna dice: "[m] i padre ha odiado la caza, es comprensible después de lo que tuvo que ver en la guerra, pero mi tío Ramón y mi abuelo han cazado para comer. A mi abuelo lo acabaron cazando (un tiro en la nuca), pero esa fue una caza infructuosa y cruel - “ (75-76). De otro lado, los compinches de Esteban, con los que él juega sus partidas de tute y dominó en el bar Castañer, tienen también su historia en esa cadena alimenticia. En este caso, ellos no son el plato comido sino los carnívoros que han aprovechado bien su presa. Por ejemplo, Justino, quién es descrito como un caníbal: "nuestro Hannibal Lecter local. El depredador [...] un tipo proteico" (64) que en el franquismo explotó a quienes emigraban de España a tierras extranjeras cobrándoles comisiones por contratos de trabajo, por residencias, por el alojamiento y hasta por protección. Bernal hijo (contemporáneo de Esteban), junto con Bernal padre son también, cada uno a su manera, partícipes en ese mundo antropófago. El primero depreda lo que su padre le ha legado: un patrimonio construido gracias a unos cadáveres del pasado. Así aparecen estos personajes en la voz de Esteban:

Aunque ahora, en estos tiempos en que el animal humano es el ser menos protegido de la creación, seguramente los ecologistas consideren más imperdonable lo de Bernal hijo que lo que hizo su padre [...] impregnar agua y barro con telas asfálticas, materia bituminosa, fibra de vidrio, asbestos cancerígenos — que es lo que ha hecho Bernal hijo nos parece más imperdonable que los asesinatos de Bernal padre. Un cadáver arrojado al mar es favor que se le hace al medio, nutriente que mordisquean los peces con sus boquitas frías. Los pecados de los pistoleros - los que llenaron las cunetas de fosas y acribillaron las tapias de los cementerios, los que nutrieron a los peces mar adentro- los absolvió la Transición, al parecer eran pecados veniales, mientras que los pecados contra el medio ambiente no prescriben, no hay juez que pueda absolverlos. No nos engañemos, un hombre no es gran $\operatorname{cosa}(44)$.

Otro "pistolero" al que "absolvió la Transición" fue al padre de Francisco Marsal, éste buen amigo de Esteban durante los años ochenta y en el presente de la narración compinche de partidas en el bar. Gregorio Marsal que en el verano de 1939 se le veía en un "[c]oche de carniceros, [en] husmeo de carroña" (80) amasó una fortuna a costa del despojo y muerte de sus enemigos, los republicanos. Es así como la familia Marsal entra a contarse dentro de los nuevos ricos que conforman una nueva clase social en la inmediata posguerra. Gregorio Marsal fue el que hizo "el trabajo sucio" y su hijo, Francisco Marsal, contemporáneo de Esteban (como del propio Chirbes), el que incrementó esa riqueza a costa de un parricidio simulado que consistió en esconder la verdad del pasado de su padre, renegando de las imágenes paternales más queridas 
como la de "José Antonio" (en clara alusión a Primo de Rivera) o escupiendo la foto de su padre falangista aunque después tuviera cuidado de "borrar la huellas del escupitajo" (185). Quisiéramos señalar aquí que la ficción de la memoria colectiva en esta narración (como en todo el ciclo chirbesiano), aunque tenga como referente a España y la historia de este país, no es una memoria nacional sino intergeneracional. Así, en esta cadena trófica es la generación que fue joven en la transición la que explota la riqueza de sus antecesores. Lo cual ocurre en todas las familias, no solamente en la de los vencedores, como es el caso de los Bernal y los Marsal, sino en la familia de Esteban cuyos antecesores fueron vencidos de la Guerra Civil.

De manera que la generación que no vivió la guerra, la llamada segunda generación, se caracteriza por ser la más sanguinaria, ya no por ser partícipe de un genocidio político, sino por consumir sin miramientos el producto del despojo que tuvo lugar gracias a la guerra o, en el caso de los vencidos, por corromper el precario patrimonio que fue cultivado con trabajo y esfuerzo. Así pues, el desorden social del presente de la narración es la herencia del "crimen originario", expresión repetida en la narrativa de Chirbes y que refiere a la Guerra Civil, violencia fundadora que inauguró un nuevo orden social. De manera, que la violencia fundadora que tiene lugar tras el triunfo de los nacionales en la guerra es también un primer momento de "acumulación primitiva de capital" o el origen de unas nuevas clases sociales. No hay duda que en esta novela de Chirbes (como en La buena letra, en Los disparos de cazador y Crematorio) este momento fundacional se reproduce a "saltos en el tiempo", es decir, "el crimen originario" y la "acumulación primitiva" (términos presentes en la narrativa de Chirbes) se repiten en determinados tiempos históricos que se legitiman ya no por las armas sino por otros medios, los de la ley. Valiéndonos de las tempranas reflexiones que Walter Benjamin plasmó en su ensayo Para la crítica de la violencia diríamos que ese momento fundacional, la Guerra Civil, se repite gracias a "la violencia conservadora" o la instancia a la ley que cada vez que se aplica lo que hace es actualizar permanentemente la "violencia fundadora". Recordemos que refiriéndose a estos momentos fundacionales, dice Ricœur, que a la celebración de unos se contrapone, de otro lado, la condena y reprobación. Así, lo que llamamos memoria es la execración de esa violencia pasada que perdura en los almacenes del recuerdo colectivo, esas "heridas simbólicas que exigen curación" (Ricœur 109). Retomando los conceptos de Benjamin, podríamos decir que, se hace memoria cuando sale a la luz la verdad de la violencia fundadora y de la violencia conservadora, es decir, la violencia del derecho y de la ley, lo que Derrida llama "el silencio encerrado en la estructura del acto fundador" (Derrida 33). De esta manera, se entiende que la Transición española, que, evidentemente, no significó el rompimiento de ese silencio, puede leerse como un salto en el tiempo que vuelve a repetir el "acto fundacional".

Pasando nuevamente a la narrativa de Chirbes, téngase en cuenta que el último gran momento de acumulación de capital y de creación de nuevas clases sociales es ficcionalizado en Crematorio (2007), novela que nos vuelve a señalar que tras todo momento fundacional hay un momento de reacomodo social. ${ }^{7}$ Pero volvamos a la novela

\footnotetext{
${ }^{7}$ No se trata pues de un momento único, sino de momentos concretos en los cuales se despoja a unos creando forzadamente una clase social que vende obligadamente su fuerza de trabajo. En la poética de Chirbes, la posguerra es un primer momento de re-acomodación de clases. Otro momento de acumulación tendría lugar en los años ochenta y noventa, así lo dice Rubén Bertomeu a través de Collado en la ficción de Crematorio: "hicimos lo que tocaba hacer, a eso los clásicos de la economía lo llamaban acumulación primitiva de capital, este país necesitaba una clase, y no tenía con qué; ahora la clase cierra
} 
que presenta el despojo, lo que ha quedado del gran banquete, los restos que han dejado las águilas rapaces. Como lo venimos señalando, En la orilla, a manera de "saltos en el tiempo" delinea la línea de dependencia entre la violencia fundadora y la violencia conservadora. En palabras del crítico y conocedor de la obra de Chirbes, Jean François Carcelén:

Hay una línea de continuidad entre el dinero negro de las fortunas conseguidas de forma sórdida durante la dictadura y del dinero fácil de los empresarios sin escrúpulos de la España de hoy. Esta sigue siendo la que nació a raíz de ese "crimen originario" (Carcelén et al. 12).

Quien se acerca a la narrativa de Chirbes constata que no es tranquilizadora ni da un ápice de tregua, no encontramos un enfoque que proponga pensar que la memoria del acontecimiento fundacional de España, la Guerra Civil, y en un salto en el tiempo, la Transición, consista en una reflexión para el perdón o la reconciliación, tampoco encontramos una postura "filiativa" o compasiva con los vencidos o despojados del "gran banquete" (Faber). Por el contrario, late una violencia y animalidad que lo impregna todo: está en el lenguaje, en el paisaje, en las caras y en los cuerpos de todos los personajes. Así, en la familia de los vencidos hay también traidores, que se consumen a su prójimo y son capaces de "matar" al padre, como pasa con Esteban.

Este hombre, nieto de ebanista e hijo de carpintero — ambos republicanos—, especulan con que, tras la inminente muerte del padre, a quien él "ayudará a morir", sus hermanos no podrán esconder el instinto devorador que los ha acompañado durante su vida y que, incluso, ha salido a flote en distintos momentos. Ocurrió, por ejemplo, el día que uno de ellos, Juan, husmeaba el dinero de su padre para invertirlo en alguno de sus negocios. Lo narra así:

[...] el perro se exaspera porque huele el orín de la liebre, la piel, y hasta husmea la sangre que bate su corazoncito, pero no encuentra la madriguera en que se refugia el animal. Jadea, gruñe, escarba, ladra el perro. Yo sí que sabía las coordenadas de la madriguera, y podía ver su boca, pero tampoco era capaz de dar un paso en el interior del agujero. En realidad la liebre no era de gran tamaño, animalito exiguo, pero se cobijaba en tres madrigueras, la CAM, Banco de Santander y Banco de Valencia [...] La liebre fui yo, yo era mi orín y mi piel, me olfateaba y cazaba a mí mismo. Me cacé y perdí la pieza. Qué se le va hacer (114-115).

Esteban habla desde el vacío del presente, en lugar de su hermano, él es quien ha hecho negocios con el dinero de su padre y el que ha perdido el modesto patrimonio que había costado años de esfuerzo y que ahora pasará a ser embargado por los bancos. El hombre se percibe al mismo tiempo como animal y como cazador, aunque como él mismo dice, percibe que no es un cazador de otros sino de sí mismo. En todo caso, sabemos que Tomás Pedrós, el socio capitalista a quien terminó por entregarle el dinero que le prestaron del banco, sí que lo ha "cazado" a él, esto desde que lo convenció

las fronteras, está el cupo cubierto, toca procurar que no haya toda esa movilidad social, ese meneo, esa permeabilidad entre clases [...] ¿Había sido en el noventa y cinco cuando había roto Bertomeu con el ruso? El año de las elecciones, el noventa y cinco y el noventa y seis, entran otros. Salgan, no vayamos a recibir una cornada de ese toro que no conocemos, que no nos conoce. Rompió con el ruso" (Chirbes $57-58)$. 
de volverse su socio paritario en la última promoción de viviendas de las tantas que ha erigido en Misent. Tomás Pedrós es el que está en la cúspide de esa cadena trófica, es un gran devorador que huye, no solo con el patrimonio familiar que Esteban le puso en sus manos, sino con las ganancias de lo que ha exprimido de los trabajadores de sus empresas. De manera que Esteban reproduce el despojo que su familia experimentó en el pasado, si bien en este caso la desposesión es por causa una traición.

De hecho, la historia del protagonista es la historia de una traición al padre que reproduce una genealogía familiar de frustraciones. Esteban es pues, el reflejo de un pasado de fracasos, en los cuales se cuenta una memoria fracasada a causa de la "desvinculación generacional" y degradación de los relatos familiares tras el quebrantamiento de los vínculos morales e ideológicos intergeneracionales (Cifre 130-131). Su monólogo esquizoide no nos conduce a una única verdad, ya que es siempre oscilante entre opuestos: la autocrítica y la autojustificación, la compasión y el odio por su padre, el develamiento de verdades que después se desdicen. Sin embargo, pese a sus contradicciones Esteban justifica todo el tiempo el acto violento que se mantiene en vilo durante toda la novela y que consiste en dar muerte al padre.

En nuestro concepto, la traición de Esteban apunta a una postura que está presente en toda la narrativa chirbesiana que consiste en una visión pesimista del ser humano y que afirma que éste nunca es inocente. Idea que Esteban repite en su largo monólogo y que está condensada en la siguiente frase: "Decir hombre es un oximorón, ¿no se dice así? Juntar dos palabras que se contradicen para crear un efecto extraño [...] Oximorón. Un silencio estruendoso, un hombre inocente" (76). Sea este el momento de señalar que la omnipresencia de la violencia en esta ficción, en nuestra interpretación, es la confirmación de que no hay pacto social vigente que cohesione a la sociedad ficcionalizada, lo cual explica que no haya un poder que monopolice la violencia. De manera que cada quien es dueño de la violencia y por lo tanto libre de ejercerla. En otras palabras, la violencia social reinante demuestra que la sociedad ha vuelto a un estado natural en donde la violencia no pertenece a ningún poder que se autoproclame fundante. Lo que reina es una violencia latente en cada personaje y que puede asaltar en cualquier momento. La vislumbra Esteban en su propia familia, es su voz la que nos traslada a un futuro próximo, al momento que vivirán sus parientes tras su muerte y la de su padre. Lo que nos presenta es una vuelta de sus contemporáneos al estado de naturaleza en una "guerra de todos contra todos", así:

A ellos, a los hermanos supervivientes, a los sobrinos, los hijos y nietos de Carmen y los de Germán, los acercará durante unas horas la codicia, hasta que descubran que los cajones de casa están vacíos y no queda nada en las cuentas, y que terrenos y domicilio y taller ya no son propiedad de la familia, entonces llegará precipitadamente el fin de esa confraternidad [...] Y al poco tiempo, tras los primeros escarceos, y el darle vuelta al tema por aquí y por allí, estallará la gran batalla, el Waterloo familiar, regreso al estado natural de la humanidad, todos contra todos por todos los medios, sin piedad ni distingos, hermanos contra hermanos, cuñados contra cuñados, tíos contra sobrinos, nietos contra abuelos primos que se enfrentan entre sí, intentando comerse unos a otros a bocado limpio (108109).

Nos situamos claramente en la visión hobbesiana que presupone un estado de naturaleza en el que el hombre es un lobo para el hombre, Homo homini lupus. Asociada con el presupuesto teórico de un "estado natural" (en oposición al social) de los hombres en 
el que reina la "guerra de todos contra todos". Estado de naturaleza en el que pervive una "violencia natural" que solo se interrumpe con el "pacto social", esto es, el paso a un nuevo orden social o civitas en cual el Estado administra la ley y monopoliza la violencia (Hobbes). La pregunta que sigue es entonces: ¿a qué apunta la postura estética en la ficción de En la orilla cuando presenta al hombre vuelto a su animalidad? En nuestra lectura, la presencia de la animalidad o de la "violencia natural" cuando se anuncia en los personajes despojados o sobrevivientes de la crisis económica y social apunta a una reivindicación. ${ }^{8}$ Es en este punto donde la violencia, el pesimismo y la crueldad, omnipresentes en esta ficción de Chirbes, anuncian la posibilidad de una justicia fuera del derecho y de la ley.

La violencia se distingue en los cinco ex-trabajadores de la carpintería que Esteban ha dejado desempleados. Su voz nos lleva por los cauces de un sentimiento paranoico, de miradas y voces que lo azuzan y que le develan una violencia a punto de estallar contra él y contra aquellos con los que él se ha asociado. Recordando el momento en que se reunió con sus empleados para avisarles del cierre de la carpintería, Esteban visualiza un gran ojo que como un panóptico lo observa y lo amenaza. Dice:

[...] un fragmentario ojo poliédrico y amenazador, ojo-polifemo al que me dan ganas de clavarle una estaca para que deje de vigilar, de acusar, de burlarse, de mendigar [...] Clavar la estaca, cegar la bestia y escapar de la trampa. Porque eso es lo que repentinamente veo, la bestia, el depredador originario, el carroñero. Descubro el fondo oscuro de hombre: el rencor de abajo (245-246).

En nuestro concepto, esta visión de Esteban articula la concepción del ser bumano vuelto a su animalidad no como una queja al caos o desbarajuste moral y social del presente de crisis, sino más bien como una reivindicación de la animalidad. Como lo dice el filósofo italiano Roberto Esposito refiriéndose a la estrategia para liberarse de la bio-política, esto es, de la intromisión totalitaria de los mecanismos estatales en la vida del ser humano:

En una tradición que siempre ha definido al hombre en la distancia y diferencia respecto al género animal — salvo para animalizar de cuando en cuando a parte de la humanidad por no ser suficientemente humana-, la reivindicación de la animalidad como nuestra naturaleza más intrínseca rompe con la prohibición fundamental que desde siempre nos gobierna. Contra el desdoblamiento del dispositivo de la persona, el animal presente en el hombre, en todo hombre y en todos los hombres, viene a significar la multiplicidad, la pluralidad, la metamorfosis. "No se deviene animal — afirma Deleuze-, sin una fascinación por el cambio, por la multiplicidad." (Esposito 203-204)

Esa "prohibición fundamental que desde siempre nos gobierna" a la que hace referencia el filósofo consiste en la prohibición de ejercer la violencia por derecho propio. Esto es, la idea arraigada de que la posibilidad de convivencia social sólo es posible gracias a la existencia del Estado o civitas que monopoliza la violencia y la ley. Es la

\footnotetext{
${ }^{8}$ Nuestra postura es opuesta a la de López Merino que en su artículo "Calas en La Caída de Madrid" (2011) distingue la visión bobbesiana de un estado de 'guerra de todos contra todos'. Sin embargo, en su interpretación se trata de una postura determinista en la narrativa del valenciano que según su interpretación "debilita la potencia narrativa y cae en un esquematismo que roza lo maniqueo: vencedor, malo; vencido bueno" (López Merino 371).
} 
misma prohibición que se invierte en la ficción de Chirbes. Retomemos la cita de más arriba de En la orilla, en la que Esteban visualizaba en sus recuerdos "el ojo-polifemo" de "la bestia, el depredador originario, el carroñero", palabras que expresan el devenir de los hombres en animales. Animalidad que ahora está en los despojados del presente o como lo dice Esteban en la "bestia" y en "el rencor de abajo". Es pues, este personaje que actualiza un lenguaje que refleja las heridas simbólicas de un pasado que él traicionó. Para terminar, queremos resaltar que la visión animalesca de los de "abajo" nos anuncia una verdad que descubre Esteban cuando hace una revisión de sí mismo y piensa en un devenir donde reina una violencia revolucionaria:

La lucha de clases, ¿no fue eso lo que creyeron mi padre y sus amigos, lo que creyó en su juventud Francisco, lo que yo ni creí ni dejé de creer pero di por supuesto? [...] Por eso desprecié a mi padre desde que tuve uso de razón. Por poner eso en el centro de su vida. Me fastidiaba oír el lamento en su boca, las imprecaciones que todo fuera arriba y abajo, ellos y nosotros. Tuyo y nuestro. Que todo acabara siendo eso. Aunque, esta tarde, ante el Polifemo de cinco pares de ojos que son uno solo, ha vuelto el lenguaje que usó hasta aburrirme: ellos soy yo y nosotros son ellos (247-248).

\section{La novia oscura. La posibilidad de una justicia dentro de un nuevo mito fundacional}

Una de las características de la narrativa de Laura Restrepo es su carácter testimonial. Es con la presencia de una narradora que se auto-representa como reportera e investigadora, y que funciona como transmisora de la información obtenida de entrevistas, documentos, archivos o testimonios, que se establece una doble referencialidad, la cual, de una parte, señala a la autora misma y a su trabajo de periodístico y, de otra, otorga autenticidad al personaje de la ficción y a su testimonio (Ardila; Capote). En la ficción de La novia oscura, la narradora llega en los años noventa a la ciudad colombiana de explotación petrolera, Tora, para investigar acerca de los carteles que comercian la gasolina de forma ilegal. Allí conoce acerca de la historia de vida de una mujer, Sayonara, que cincuenta años atrás había vivido en esa ciudad y había sido parte de los conflictos sociales y económicos en los que se imbuye ese territorio. De manera que esta ficción conjuga un "cronotopo compuesto", de una parte, el pasado narrado correspondiente a la primera parte del siglo XX y, de otra, un presente desde donde se narra y que corresponde a los años noventa (Lauge Hansen). ${ }^{9}$ Cronotopo que conecta el marco ficcional (contextual) y contextual (referencial), si tenemos en cuenta que la autora en la realidad recibió financiamiento de la empresa Ecopetrol en los años noventa para hacer una investigación periodística sobre el tema de la gasolina (Manrique 364-365). Hecho que en el marco ficcional se cuenta así:

Andaba haciendo a contrarreloj un reportaje sobre un asunto sin relación alguna, el robo y la distribución clandestina por parte de una organización criminal que la gente llama el cartel de la gasolina y para eso aterricé en Tora un martes a las once de la mañana en una

\footnotetext{
${ }_{9}$ Consideramos fructífero utilizar el concepto de "cronotopo compuesto" aunque el experto en narrativas de la memoria la haya propuesto en el marco de la novela memorialista española actual.
} 
avioneta de la compañía Aces. A las dos de la tarde la Sayorana ya se había atravesado en mi camino (142).

El cronotopo del presente-pasado comparte el eje territorial del Tora, que es el nombre indígena de la ciudad colombiana llamada actualmente, Barrancabermeja. Por lo cual, Tora refiere al centro urbano del Magdalena Medio, donde se encuentran en la actualidad los yacimientos de petróleo más importantes de Colombia. Lugar donde estuvo asentada la Tropical Oil Company, en la ficción llamada "la Troco", empresa que en la segunda parte del siglo XX, por las presiones del movimiento obrero, pasó a ser propiedad de la nación y tomó el nombre de Ecopetrol. De ahí que este territorio sea conocido por diferentes conflictos históricos: las luchas del movimiento obrero, la resistencia indígena que se ha opuesto a la explotación del territorio a lo que se suma, en la segunda parte del siglo XX, la presencia armada de guerrillas (ELN, FARC entre otras) pero también de paramilitares, fuerzas armadas estatales y transnacionales. ${ }^{10}$

Sin embargo, este panorama conflictivo del cronotopo del presente aparece en la ficción solamente como un paisaje exterior aunque, ciertamente, está relacionado con la intra-historia del mundo de la prostitución del barrio llamado La catunga, que es central en esta narración. El protagonismo lo adquieren las prostitutas del barrio cuyos relatos nos introducen en el discurso de la memoria, son ellas quienes definen la perspectiva de la historia cuando recuentan lo que vivieron en la primera parte del siglo $\mathrm{XX}$, época en la que conocieron a Sayorana, la prostituta más conocida de la zona. Ella, verdadera protagonista de la historia, es, sin embargo, una voz ausente que se nos presenta en la narración a partir de lo que cuentan de ella, en este camino las constantes alusiones a su corporalidad y a su lugar en esta sociedad anclada en la economía petrolera deviene una metáfora del cuerpo político y social, esto si tenemos en cuenta que todo orden político está estrechamente relacionado con un orden corporal determinado (Foucault; Rancière). Es en este punto donde esta ficción entrecruza dos constantes de la narrativa de la autora: mito e historia (Capote; Lirot; Mejía). Como pasaremos a ver, esta ficción se interesa por reformular los mitos fundacionales ligados con la violencia y emparentados con el "hecho colonial", a partir de los cuales la sociedad narrada funda su orden u organización social.

Retomar en la ficción figuras dotadas de significado fundador (Colón, Felipe II, archivos o atmósferas naturales) ha sido una de las constantes de la literatura latinoamericana para reescribir y resignificar los relatos de identidad y de poder hegemónicos en que esta sociedad está inmersa (González). En La novia oscura el relato fundador se incorpora reconstruyendo la identidad de Sayonara quien, como descubre la narradora, es hija de madre indígena y padre blanco colono o colonizador. ${ }^{11}$ Su genealogía mestiza

${ }^{10} \mathrm{El}$ informe del Centro Nacional de Memoria Histórica "Memoria de la infamia. Desaparición forzada en el Magdalena Medio" (2017), da cuenta de que en los años noventa, tiene lugar en Colombia un proyecto paramilitar de dimensión nacional que toma cuerpo en las llamadas Autodefensas Unidas de Colombia (AUC). La dirigencia de este proyecto es una alianza entre narcotraficantes, ganaderos, políticos, tanto del nivel local como nacional, y militares, cuyo objetivo es retomar control sobre el territorio y combatir a las guerrillas de izquierda. Estas tenían presencia y control en gran parte del país. En el área del Magdalena Medio, por ejemplo, la presencia de la guerrilla del ELN ha sido histórica $(\mathrm{CNMH})$.

${ }^{11}$ El colono es un trabajador despojado que llega a zonas selváticas en condiciones muy adversas y en momentos coyunturales de explotación de recursos naturales. Se asienta en una finca construida con base en deudas adquiridas con los comerciantes, de manera que con el tiempo sus «mejoras» pasan 
y su triple identidad: "la niña", como se le conocía en Tora tras llegar desplazada de su lugar de origen; "Sayorana", nombre que toma para ejercer la prostitución en el barrio de La catunga; y "Amanda", nombre original que retoma la protagonista en un periodo que abandona la prostitución. Todas estas denominaciones funcionan para exponer la temática fundacional y la intermitencia de la identidad (Martín).

La identidad mestiza de la protagonista funciona como arquetipo de la identidad del mestizo y su historia genealógica puede leerse como una mimesis del relato de la identidad híbrida producto de la historia colonial, aunque esta vez el relato se construye desde la historia colombiana del siglo XX donde los términos colonizador o colonización refieren, como lo hemos dicho, a una forma de producción y de vida. Vayamos al relato sobre el encuentro entre Abelardo, padre de Sayorana, con Matilda, la madre, el cual llega al lector mediado por la voz de la periodista-narradora que mantiene un diálogo con la familia Mantilla, así:

Digamos más bien que la cazó, pero con zeta, en una de esas cacerías que organizaban los colonos blancos en los Llanos Orientales [...] Cuentan que para que no los mataran me dice el señor Mantilla-, los guahibos gritaban que ellos también eran hiwi, que es su lengua nativa quiere decir gente. [...] Abelardo, el antioqueño, quiso traérsela viva. Como tenían nombre pagano y hablaba en lengua salvaje, él la bautizó Matilde y le enseño el español, que era idioma de gente (180).

La repetición de la violencia fundadora colonial se conjuga aquí con la historia y la memoria, así la violencia y la identidad pueden leerse como transfiguraciones del momento fundacional cuyo relato se reproduce, aunque transformado en el tiempo. Lo interesante de este nuevo relato genealógico es que ambos, el hombre blanco y la mujer india, en el orden social histórico del siglo XX, son despojados y expulsados de tierras que son apropiadas por otros. Ambos personajes refieren pues, a la historia de Colombia que, como dice Alfredo Molano, "es la historia de un desplazamiento incesante" (Molano, Desterrados 15). En este sentido, es interesante que la narrativa de Restrepo que reescribe los acontecimientos históricos de Colombia esté poblada de personajes que están en constante desplazamiento. En el caso de La novia oscura, todos los personajes que llegan al pueblo de Tora vienen de otra ciudad.

En Tora, la Tropical Oil Company, se autoerige como el centro gravitacional que define la organización socio-económica de la comunidad, ya que es la empresa la que causa la migración masiva de hombres que buscan ser "petroleros" y es a su vez la que determina un nuevo orden social que reproduce las históricas divisiones de clase, género y raza. Incluso, es la que regula la arquitectura o distribución del espacio territorial al cual pertenece cada estrato social. En este punto, la narración deja en evidencia como la empresa no es solamente un poder económico, sino un poder que pretende regular a la sociedad introduciendo una moral que demanda la formación de una familia y unas normas religiosas que conformen, de una vez por todas, una sociedad disciplinada y subordinada.

a manos de los acreedores, que las concentrarán como haciendas. Así la "colonización” es un proceso de ampliación latifundista de la frontera (Molano, "Fragmentos"). En otras palabras, el colono es un trabajador permanente expulsado de los territorios que va "colonizando": primero, es desplazado de su lugar de origen por el minifundio; después, de tierras nuevas y baldías por el latifundio y finalmente, desplazado por la violencia política. 
Es a esta pretensión de estructuración social a lo que Jacques Rancière llama "policía", es decir, la regulación estática de "lugares, funciones o sistemas" que define "la ausencia de parte" de unos en una sociedad (Rancière 44). En La novia oscura hay una tensión permanente entre los habitantes de Tora y la Troco que amenaza con consolidarse como "policía" o potestad reguladora de los lugares y funciones de cada cual. Lo que dilucidamos son órdenes sociales que conviven en un mismo territorio y que no terminan por eliminarse mutuamente. Esto quiere decir que no hay un único y definitivo acontecimiento fundador. Lo que advertimos son dos poderes que pretenden ser fundacionales, cada uno de ellos, se auto-justifica así mismo. Así, de una parte, está la Troco que ha instalado en ese territorio selvático y tropical que es Tora "el mítico e impenetrable Barrio Staff [...] una réplica reducida a escala del american way of life" (212). Esta zona artificial es donde se ubica el área residencial del "personal norteamericano" (213). Este barrio está pensado también con funciones represivas, hay que recordar que a la hora de las protestas de los trabajadores de la empresa los prados verdes del Club de Golf funcionaban como una "auténtica fortaleza" de refugio para el personal norteamericano, mientras que la cancha de béisbol era convertida en "prisión provisional" (298). Aquí merece la pena resaltar que esta ficción entronca con la narrativa colombiana que denuncia y narra la "violencia" de multinacionales contra los obreros y la comunidad (Osorio; Capote). ${ }^{12}$ La cual, se integra en esta ficción en la atmósfera de la violencia política entre liberales y conservadores a mediados de siglo. Nuevamente, en la narrativa de ficción colombiana se visibiliza la alianza entre Estado y capital transnacional, donde el primero solo aparece en momentos de fuerte represión a los trabajadores y la población beligerante..$^{13}$ Lo particular de esta narración es que se sitúa desde el punto de vista de unos personajes poco presentes en la ficción que reescribe la historia, las prostitutas, que aquí se auto-incluyen en la revisión de acontecimientos históricos de resistencia poco o nada visibilizados en la historia oficial.

Ahora bien, el otro espacio social que se contrapone al orden social demarcado por la explotación de la empresa es el de las prostitutas. Son ellas las que definen, el desorden presente en Tora y que se vive abiertamente en La catunga, barrio que ellas han fundado. Así se lo dice la prostituta más vieja del barrio a la narradora-entrevistadora: "Entienda que a Tora la fundamos nosotras las prostitutas según nuestra propia ley [...] — me dice Todos los Santos, soberana y bien plantada, pese a la demasiada edad" (13). Este orden social de La Catunga, donde rigen otras leyes, aunque esté al margen de la sociedad, no es en absoluto ajeno a lo que ocurre en Tora, lo cual se evidencia en algunos momentos decisivos para la población. Un punto álgido de enfrentamiento

${ }^{12}$ La "violencia", con minúscula, se refiere a la violencia como categoría narrativa e histórica que consiste en La Guerra de los Mil Días, la violencia bipartidista de los años cuarenta y cincuenta, las masacres de las multinacionales bananeras y del caucho, la violencia guerrillera, paramilitar y el narcotráfico. Es decir, refiere la violencia como fenómeno que atraviesa el largo de la historia de Colombia y no solamente a, La Violencia, con mayúscula, que alude a la narrativa sobre la guerra civil de los años cuarenta y cincuenta.

${ }^{13}$ Una de las características en las movilizaciones y luchas obreras contra la Tropical Oil Company ha sido la alianza de la población, la cual se ha sumado a las peticiones de los obreros de la compañía. Así pues, ha sido con la solidaridad activa de comités de agitación, propaganda, alimentos, vigilancia, y con el apoyo de la población que se ha generado una cadena de resistencia civil. Alfredo Molano resalta de esta alianza el apoyo que recibieron los trabajadores por parte de los campesinos y colonos de la región, que se unieron a las peticiones de los obreros en 1924 en la Huelga del Arroz. Alianza que en pleno siglo XXI, según dice, está vigente (Molano, "Fragmentos”). 
entre el orden social de La Catunga y el de la empresa tiene lugar en la llamada buelga del arroz, en la cual las prostitutas, según relata la narradora:

Contagiadas por la pasión insurreccional [...] entraron en la huelga de piernas caídas en adhesión a los petroleros [...] se lanzaron a las calles, junto con la población en general, a participar de los foros que se armaban en cada esquina y a protagonizar manifestaciones y multitudinarios desórdenes en apoyo al pliego de peticiones y, por añadidura cívica, para exigir acueducto y alcantarillado en los barrios de Tora, que ardían de sed y de sequedad (298).

La histórica huelga del arroz tuvo lugar en los años veinte cuando cerca de 3000 trabajadores de la multinacional petrolera repudiaron las bolas de arroz con grasa con que los alimentaban y exigieron una serie de mejoras básicas de salubridad y, por supuesto, un salario digno. En la reconstrucción de este hecho histórico las prostitutas dejan claro que su presencia fue decisiva para el mantenimiento de la huelga. Gracias a ellas los huelguistas pudieron, por ejemplo, tomarse cada uno de los campos o plantas de petróleo durante días, tener acceso a alimentos, disponer de periódicos impresos y correos que informaban el paso a seguir de los trabajadores y de la población según el curso de las negociaciones con la patronal. El desorden general en Tora y la solidaridad entre los asalariados y las prostitutas puede leerse en términos benjaminianos como una "violencia revolucionaria". La huelga es según el autor de Para la crítica de la violencia la única situación que permite pensar la homogeneidad del derecho y de la violencia, la violencia como el ejercicio del derecho y el derecho como ejercicio de la violencia. Es lo que Benjamin llama "violencia contra violencia" (Derrida; Benjamin, Violencia).

En nuestro concepto, hay una duplicidad en la postura de la narradora de La novia oscura con respecto a esta violencia. En un primer momento, la simpatía de la narradora por esos momentos de violencia revolucionaria, en que la sociedad se rebela ante lo que considera injusto poniendo en peligro el orden dado y queriendo fundar otro orden nuevo, es evidente. Su voz nos señala ese momento excepcional de poder que es la huelga, como el acontecimiento que en esta ficción pone en conjunción dos mundos: el de las prostitutas y el de los asalariados de la Troco. Y refiriéndose a este momento en el que la sociedad apunta a destruir el orden que impone la empresa, la narradora habla de un:

erotismo comunitario que en ciertos momentos excepcionales electriza el aire, invitando a creer que la felicidad es posible que la vida es generosa, que se puede domeñar la soledad y el aislamiento, que está en manos propias el lograr por fin que al día de hoy lo siga un mañana, y a ese mañana un pasado mañana, en una rutilante sucesión de futuro que no conocemos los colombianos (297).

Ese "erotismo comunitario" al que refiere la narradora se articula desde el comienzo de la novela con el triángulo de amor compuesto por dos hombres que desean a una misma mujer. En efecto, la estética de la violencia de esta ficción dialoga con la concepción de la violencia de René Girard. ${ }^{14}$ Concretamente, el triángulo de amor que hace evolucionar la novela, que consiste en la relación entre los dos hombres -

${ }^{14}$ Es bien sabido que Laura Restrepo es admiradora del filósofo y antropólogo René Girard y ha expresado que su novela Leopardo al sol ha sido construida bajo la plantilla de las concepciones de Girard sobre la violencia, la venganza y lo sagrado (véase Melis). 
Sacramento y el Payanés - y su deseo por la prostituta Sayonara, se construye a partir de la idea de la condición imitativa del deseo y su propensión violenta: el deseo es el deseo del otro. Es decir, el deseo es imitativo, se desea lo que otro también desea, cadena amenazadora que genera una rivalidad, "crisis mimética", en palabras de Girard, o "violencia de todos contra todos", en términos bobbesianos (González 165). Es en este nivel en el que la narración expone una advertencia moralizante al lector, al cual se le anuncia que la violencia de todos contra todos, no se apacigua en esta sociedad, por el contrario, desemboca en nuevas formas de enfrentamiento y pudiera conjurarse en el momento indicado, absteniéndose de ejercerla. De lo contrario y como se deja ver En la novia oscura lo que deviene es una espiral en que la violencia toma diversas caras. Como lo dice Sacramento, petrolero que se enfrenta a la amenazante selva: "Aquí nada es lo que parece y todo adquiere el don de transformarse en su contrario. Lo único seguro es la angurria con que te mira la selva; te descuidas un instante y eres hombre masticado" (91).

La ficción de Restrepo más que reconstruir la memoria de períodos históricos lo que busca es la reconstrucción de los sujetos, en este caso, de las prostitutas, que forman parte de una generación que ha visto la guerra ininterrumpidamente durante el siglo XX y parte del XXI. Hay que señalar que esta ficción nace de sus entrevistas en el barrio de las prostitutas donde la escritora evidencia el "deseo de contar y de que las contaran", incluso, el lanzamiento de la novela tuvo lugar en Barrancabermeja donde sus habitantes podían sentirse parte de la obra (Monserrat 189). Así pues, la ética-política de esta ficción consiste en devolver a las entrevistadas una vida convertida en relato y mito, exaltando su dignidad y visibilizando su valía en momentos decisivos e históricos de uno de los lugares que ha sufrido de la forma más denigrante la guerra.

Dicho esto, hay que señalar que el heroísmo de los despojados en esta ficción redunda con una postura que pareciera negar el conflicto, nos referimos a que el acuerdo y unión entre partes que en principio se enfrentan y se excluyen niega la histórica exclusión que ha sufrido una parte de la sociedad colombiana. ${ }^{15}$ Así, en la ficción de La novia oscura resulta ingenuo, por ejemplo, que Brasco, ex directivo de la Troco, llegue a ocupar el lugar de una víctima que injustamente es linchada por los trabajadores. La narradora lo pone en el lugar del "chivo expiatorio" contra el cual descansa la violencia de todos, lo que el admirado filósofo de Laura Restrepo, René Girard, define como el momento en que la violencia de "todos contra todos" se convierte en la "violencia de todos contra uno". Así, la huelga pierde su excepcionalidad como momento revolucionario en el que se conjuga la violencia y derecho, o como diría Derrida refiriéndose a este tipo de momentos, aquella violencia que se presenta "como teniendo derecho al derecho" (Derrida 90) para pasar a convertirse en un momento de crisis social seguida por la unión de partes que en principio están en conflicto (caso de Brasco, ex-dirigente de la empresa, con las prostitutas y los trabajadores). Todo esto rematando con un final feliz que sugiere un nuevo mito, al que la narradora llama el mito de la "puta y el petrolero", que apunta a la posibilidad de comenzar de nuevo en

15 Sobre la ideología del amor cortés que impregna el mundo de la prostitución y sobre la reproducción de esquemas y roles tradicionales de género en esta ficción, hay visiones encontradas (véase Capote; Lirot; Martin). En nuestro, concepto la postura conciliadora de la narradora-autora juega un papel determinante en la negación de conflictos que develan lo inconmensurable o imposible de un lenguaje común entre partes (Rancière). 
otro lugar, pero sin resolver ninguno de los conflictos que se plantean desde el principio de la novela como son, la exclusión, la represión del poder estatal y transnacional.

\section{Bibliografía}

Ardila Jaramillo, Clemencia. "De la realidad a la ficción. De la literatura al periodismo". Co-herencia 12.22 (2015): 227-248.

Basanta, Ángel. "La trayectoria novelística de Rafael Chirbes". Convocando al fantasma, novela crítica en la España actual. Ed. David Becerra Mayor. Madrid: Tierradenadie, 2015. 25-56.

Botero Bernal, Andrés. "Derecho y literatura: un nuevo modelo para armar. Instrucciones de uso". Implicación derecho y literatura. Ed. José Calvo González. Granada: Comares, 2008. 29-40.

Benjamin, Walter. Para una critica de la violencia y otros ensayos. Iluminaciones IV. Madrid: Taurus, 1991.

Benjamin, Walter. Sobre Kafka. Textos y apuntes. Buenos Aires: Eterna cadencia, 2014.

Capote Diaz, Virginia. Reeescribir la violencia. Narrativas de la memoria en la literatura femenina colombiana contemporánea. Bruselas: Peter Lang, 2016.

Calvo González, José (Ed.). Studi Ispanici. Derecho y literatura hispánica. Pisa/Roma: Fabrizio Serra, 2014.

Carcelén, Jean François et al. "Rafael Chirbes, en Beniarbeig”. Ínsula 803 (2013): 1321.

Cifre Wibrow, Patricia. "Memoria y posmemoria en la narrativa de Rafael Chirbes". Conflictos de la memoria/Memoria de los conflictos. Modelos narrativos de la memoria intergeneracional en España e Italia. Ed. Leonardo Cecchini y Hans Lauge Hansen. Copenhague: University of Copenhagen, 2015. 127-140.

Chirbes, Rafael. En la orilla. Barcelona: Anagrama, 2014 [2013].

Derrida, Jacques. Fuerza de Ley. El "fundamento místico de la autoridad". Madrid: Tecnos, 1997.

Esposito, Roberto. Comunidad, inmunidad y biopolítica. Madrid: Editorial Herder, 2009.

Eusebio, Carmen de. "La tensión en el lenguaje debe entenderse como tensión en el proceso de aprendizaje al que se somete al lector" [entrevista con Rafael Chirbes]. Cuadernos hispanoamericanos 757.8 (2013): 247- 257.

Foucault, Michel. Historia de la sexualidad I. La voluntad de saber. México: Siglo XXI, 1984.

Faber, Sebastiaan. "La literatura como acto afiliativo: la nueva novela de la Guerra Civil (2000-2007)". Contornos de la narrativa española actual (2000-2010). Ed. Pedro Álvarez Blanco y Toni Dorca. Madrid: Iberoamericana, 2011. 101-110.

González Echeverría, Roberto. Mito y Archivo. Una teoría de la literatura latinoamericana. México: Fondo de la Cultura Económica, 2011.

González Hernández, Domingo. Hacia una teoria mimética de lo político: René Girard y su escuela. Tesis. Universidad Complutense, 2015. Web. 30 diciembre 2020.

Hobbes, Thomas. Leviatan o la materia, forma y poder de un república eclesiástica y civil. Ciudad de México: Fondo de Cultura Económica, 2017. 
Labrador, Germán. "En la orilla de Rafael Chirbes: proteínas y memoria”. Turia 112 (2015): 225-234.

Lauge Hansen, Hans. "El cronotopo del pasado presente. La relación entre ficcionalización literaria y lugares de reconocimiento en la novela española actual de la memoria". La memoria novelada II. Ficcionalización, documentalismo y lugares de memoria en la narrativa memorialista española. Ed. Juan Carlos Cruz Suarez y Diana González Martín. Bern: Peter Lang, 2013. 23-41.

Lirot, Julie. "El desarrollo de la mujer protagónica: visiones opacas y cuerpos transparentes". El universo literario de Laura Restrepo. Ed. Elvira Sánchez Blake y Julie Lirot. Bogotá: Taurus, 2007. 159-172.

López Bernasocchi, Augusta y José Manuel López de Abiada "Hacia la Larga Marcha, de Rafael Chirbes. Guía de lectura". La constancia de un testigo, ensayos sobre Rafael Chirbes. Ed. Augusta López Bernasocchi y José Manuel López de Abiada. Madrid: Verbum, 2011. 219-278.

López Merino, Juan Miguel. "Calas en La caída de Madrid”. La constancia de un testigo. Ensayos sobre Rafael Chirbes. Ed. Augusta López Bernasocchi y José Manuel López de Abiada. Madrid: Verbum, 2011. 370-385.

Manrique, Jaime. "Entrevista con Laura Restrepo". El universo literario de Laura Restrepo. Ed. Elvira Sánchez Blake y Julie Lirot. Bogotá: Taurus, 2007. 353-367.

Mate, Reyes. La piedra desechada. Madrid: Trotta, 2013.

Martin, Deborah. "Mothers and Nomadic Subjects: Configurations of Identity and Desire in Laura Restrepo's La novia oscura". The Modern Language Review 103 (2008): 113-128.

Mejía, Gustavo. "Historia e historias en La novia oscura de Laura Restrepo". Revista de Estudios Colombianos 21 (2009): 14-19.

Molano, Alfredo. Desterrados, crónicas del desarraigo. Bogotá: Ancora, 2001.

Molano Alfredo. "Fragmentos de la historia del conflicto armado (1920-2010)". Comisión Histórica del Conflicto y sus Victimas. Contribución al entendimiento del conflicto armado en Colombia. 2015. Web. 30 diciembre 2020.

Osorio, Oscar. "Siete estudios sobre la novela de la Violencia en Colombia, una evaluación crítica y una nueva perspectiva". Poligramas 25 (2006): 85-108.

Rancière, Jacques. El desacuerdo, política y filosofía. Buenos Aires: Nueva Visión, 1996.

Ricœur, Paul. La memoria, la historia, el olvido. Madrid: Trotta, 2003.

Roggero, Jorge (Ed.). Derecho y Literatura: textos y contextos. Buenos Aires: Universitaria de Buenos Aires, 2015.

Winter, Ulrich. "Memoria histórica e imaginación jurídica: políticas estéticas de la memoria, desde la justicia poética al forensic turn". Memoria y Narración 1 (2018): 184 197.

Valls Fernando. "La narrativa de Chirbes entre las sombras de la Historia". Turia 112 (2015): 127-145. 